\title{
New Approach to Resources Monitoring for Transport and Infrastructure Construction
}

\author{
Dmitriy Silka ${ }^{1, *}$ and Vadim Kankhva ${ }^{1}$ \\ ${ }^{1}$ Moscow State University of Civil Engineering,26, Yaroslavskoye shosse, Moscow,129337, Russia
}

\begin{abstract}
Resources monitoring in the market economy is carried out to determine current market prices. Market pricing depends on a huge list of factors and in each case is carried out in a wide range of initial values with high probability assumptions. This approach is based on a set of organizational and economic mechanisms allowing tracking not potential, but real purchase and sale of construction resources. Systematization the received information allows planning and implementation of state construction contracts in the field of transport and other dispersed construction.
\end{abstract}

\section{Introduction}

Infrastructure construction, which among others includes creating transport facilities in the form of various means of communication, is highly capital-intensive and geographically dispersed. A considerable amount of these projects is carried out by the state, as based on experience of many countries, only the state is able to implement projects with a payback period of a few decades. Moreover, the state centrally accumulates budgets, which allows long-term financing. In other cases, projects are carried out using schemes of public-private partnership. Alternatively, they are carried out by businesses also having an industry scale. For example, companies in the field of railways construction, where the key role is played by Russian Railways JSC, in the field of gas industry - by Gazprom PJSC, NOVATEK OJSC, etc. are transnational corporations (TNCs). And as we know, TNCs' activities are comparable to economies of small countries. At that, such TNCs reflect the scale of the industry quite widely [1].

\section{Methods}

Efficient implementation of capital-intensive programs and projects is critically dependent on the stage of pre-project studies. A long construction period entails adjustments to the planned calculations. The more precise are initial figures, the smaller are the deviations in the course of work. Businesses, and especially the state, try to systematically address problems of preparation stage. Since starting any project is usually associated with investments justification, preliminary calculation of the design work cost becomes a key

*Corresponding author: w220@yandex.ru 
issue. Modern tasks of planning and execution of capital-intensive programs and projects, including those involving implementation of infrastructure, transport facilities, construction of buildings and structures, as well as their overhaul and repair, reconstruction, restoration and renovation are carried out in conditions of market pricing formed under the influence of supply and demand, which makes it impossible to reliably identify future prices and requires their constant monitoring. Such pricing depends on a huge list of factors of the entire economy, and in each case is carried out in a wide range of initial values with large probabilistic assumptions. Supporting management decisions both in the area of state contracts, where there is a single concept of public procurement for all industries in general, and in the field of private investment, to the great extent depends on the possibility and quality of preliminary assessment of the cost of all the resources that will be needed in investment projects. Therefore, providing pricing based on principles of maximizing the correspondence between planned and actual calculations is only possible if it is an organized and managed process [2,5].

For public procurement, we need a mechanism providing obtaining information on the cost of various construction resources acc. to uniform principles throughout the country. Handling actual cost data also allows creating highly accurate predictive models taking into account the inflation index, etc. Then we can plan new construction programs based on uniform principles, make different comparisons and analysis in territorial aspect, make better choices between options and alternatives. At that, it is difficult for many branches to implement the scheme of arranging information exchange with individual resources suppliers for continuous collection and processing of prices. For example, transport construction is carried out taking into account high mobility of production facilities and construction objects themselves. Constant change of location of companies building roads, railways, ports, channels, and other facilities of water, air and pipeline transport does not allow focusing on the same suppliers of construction resources for a long time and requires data from different territories. Such areas as transport construction highlight the shortcomings of decentralized system of collecting information about the cost of construction resources, which is a feature of the Russian economy. In fact, in each region of the Russian Federation, its own set of construction resources should be monitored. Although the main cost driving resources are cement, gravel, ready-mix concrete and reinforced concrete products, reinforcing materials, metal structures, and many others, there are plenty of unique materials in territorial aspect. Information is collected manually, by phone interviews and asking suppliers. Resources being followed are not always sufficient for the purposes of investors giving rise to new projects [3].

Thus, the state is the first to try to unify approaches for monitoring resource costs. But since in addition to state contracts, private entrepreneurs also need reliable price data in the market economy, the country needs to develop a new resource monitoring methods system. A serious increase in information flow in all sectors of economy and society now is accompanied by a quick growth of feasibility of data collecting, processing and transmission. Up-to-date technologies in this area make manual information collecting methods completely irrelevant. Now in various fields of national economy they create a lot of various data processing systems, data processing centers. Such systems are in demand as part of the new industrial policy in the field of construction, manufacturing industry, infrastructure and transport development of the country, etc. But still there is no transparent understanding of how such a system should be organized and operate in the sphere of circulation of production resources, production equipment. Therefore, a new resource monitoring concept considered in this article is forward-looking, and the main thing is extremely necessary both for the state and businesses. Taking into account its overall economy significance, orientation for economic development, rather than interests of 
individual businesses, we propose to create production resources monitoring mechanism through creating a new state institution [4].

\section{Results}

Implementation of the proposed concept influences the sphere of economic interests and relations affecting both public authorities and the business community. If we consider the transport construction, we can note the following. Transport construction involves construction of facilities and accompanying infrastructure associated with the transport sphere. This sphere is wide and includes land, air, sea and river, as well as underground and pipeline transport. Transport sector includes a huge number of facilities: is not only a road or a railway. We take into account electrification of all the systems and creation of related components and systems: railway stations, air terminals, berths and other facilities. A separate subsector of the transport sector is subway construction, which now takes place continuously. Thus, solving the transport problem of the Russian Federation consists of hundreds and thousands of different projects. If additionally we consider industrial and civil construction, it is possible to substantially increase the amount of processed data on resources, thus confirming the need for refusing situational solutions in favor of system solutions for data collection and processing $[6,9]$.

1. The main method of solving the existing problems is integration of the new production resources cost data collection and processing mechanisms with the existing federal contract system. Recently, the federal contract system has been showing a tendency to budgetary saving, which is expressed in a constant effort to minimize the initial contract price, but not to increase its objectivity. In practice, this leads to increasing risks of underfunding projects and the need for additional funding. For example, actual results of interaction of the state as a customer and contractors based on statistical data are shown in Table 1.

Table 1. Actual financing of state contracts of all territorial entities of the Russian Federation (94-FL)

\begin{tabular}{|r|c|c|c|c|}
\hline \multicolumn{2}{|c|}{ Contract data } & \multicolumn{4}{|c|}{ Payment period of the contract } \\
\cline { 2 - 5 } & 2011 & 2012 & 2013 & 2014 \\
\hline $\begin{array}{r}\text { Price of completed contracts } \\
\text { (bln.RUR) }\end{array}$ & $1,589.9$ & $1,701.1$ & $1,391.7$ & $1,083.8$ \\
\hline $\begin{array}{l}\text { The amount actually paid under } \\
\text { these contracts (bln. RUR) }\end{array}$ & $1,789.1$ & $1,976.3$ & $1,663.6$ & $1,354.6$ \\
\hline Difference: & & & & \\
\hline bln. RUR & -199.2 & -275.2 & -271.9 & -270.8 \\
\hline$\%$ & $12.5 \%$ & $16.2 \%$ & $19.5 \%$ & $25.0 \%$ \\
\hline
\end{tabular}

Every year the number of contracts suffering from a violation of the works order due to lack of funding increases. This entailed the need for new tenders and auctions, and generally missed deadlines, loss of time. One of the reasons for this situation is too wide price range on building resources, information about which is considered at pre-design and design stages. In many cases instead of using actual prices they use indices of resource groups, or even types of work, while these data may be refreshed as rare as once every three months. Indices are used within the reference-index method for calculating construction cost. While is it obvious that resource method is more accurate. It is based on data about cost of exactly those resources that are used in the project. But the Russian government and the construction industry experts recognize that the resource method cannot be used widely, as there is no system of adequate construction resources monitoring in the country. And the 
prices systematized in periodic collections by individual businesses are not enough reliable [7].

So, the proposed concept is based on a combination of organizational and economic mechanisms. Rosresurs - a new institution - can operate them and has competence to observe the formation of the cost of production resources without committing to any specific industry. At that, this body should be responsible for monitoring the results of pricing of material resources in the market conditions, as well as for information modeling and supporting the processes of pricing of material items of real estate at all stages of their creation. The system of measures for implementation of such a state function is defined as part of the federal cost monitoring (FCM). The main content of such monitoring, as well as its principal novelty is fixing prices for resources based on results of actual purchase and sale transactions rather than potential intentions of suppliers, like now. Currently, there is no concept of federal cost monitoring in the scientific and practical use. At that, according to the author, it is a constituting element of cost engineering and it has its own specific functionality and scientific and practical value [8].

Real estate sphere and construction activity generally by the end of 2015 showed the volume of state orders in the amount of 2 trillion RUR, as well as reflected spending of 4 trillion RUR of state corporations investments. All design studies for implemented projects, although to different degrees, used data of cost monitoring, which is currently not systematically positioned. It is obvious that such funds deserve special attention. The state customer not aware of its possibilities based on available funds turns out to be unable to implement the planning mechanism that would guarantee achieving the final result at a given amount of allocated investment funds. If there is no effective planning conditions, it is impossible to implement the complex programs of improving investment activity.

2. The scale of the problem to be solved is unprecedented and requires a new data processing method. Taking into account existing experience of collection and processing data about cost of resources in the country, as well as already chronic problems of entire inadequacy of the data obtained, to solve the tasks adequately, we need new generation technologies. The amount of information on actual buying and selling transactions, which require monitoring and further system processing, allows us to identify the database, which, according to international classification refers to "Big Data" type. The concept is relatively new, it emerged in the late 2000s. Current tendencies of avalanche growth of digitized information for understanding what is happening do not presuppose any alternatives. But as a result, this is followed by creating new technologies to work with the flow of information. The tendencies are not so dramatic on a low-scale level, especially taking into account underdeveloped sector management system. But on a professional level, we can see actually formation of new sub-sectors. "Big Data" is actually a series of approaches, tools and methods for handling structured and unstructured data of huge volume and considerable variety to obtain results understandable for people, effective in the conditions of continuous growth, distribution on multiple units of the computer network. Experts predict that introduction of big data technologies will influence the most, among others, the state management.

The size of a database, which Rosresurs is expected to generate, fully meets "Big Data" parameters with all the consequences. The main result of Rosresurs' activities is keeping an up-to-date database of the cost of construction resources on the territory of the Russian Federation. Such a resource should be referred not generally to the territorial entity of the Russian Federation or some of its areas, but to geographic coordinates of the place of its sale. Actually, it is any point of the country. Therefore, the volume of data potentially processed by Rosresurs institution can be expressed as follows. In the construction industry, public authorities publish a Federal Collection of Estimate Prices (FCEP) for estimate pricing purposes. Only for the construction industry, it contains about 60 thousand items. 
But these items are used in almost all the country's economy and its business processes for solving problems of construction pricing in many sectors. Ministry of Construction of the Russian Federation in recent years has the aim to increase the resources range to 300 thousand items. Let's assume the final goal will not be reached in the nearest future, and at some point in the medium term, the collection will contain $2 / 3$ of the target value, i.e. 200 thousand items. According to the results of all-Russian census of population in 2010, 1108 settlements in Russia have the city status. Each city may have much more than one seller of a particular resource. Plus we should add non-city settlements, lots of sales of goods in one place during a day or a month, etc. Thus, each item, due to territorial dispersing of suppliers and sales transactions, will simultaneously be in databases, let's say 1000 times with different costs. If we monitor well and understand, that some resources may be identified simultaneously in different regions of the Russian Federation even more than 1000 times, we should provide even greater volume of sampling. As a result, we may forecast that the general database will contain:

200 thousand items totally $* 1000$ items and variations of each $=200$ million items

where: Rosresurs institution will define the average resource value in relation to time, territory, etc., from these 200 million items using algorithms of its information system, including conditions in accordance with the requirements and objectives of the final user of such information. Moreover, if we assume that information is aggregated monthly, and the Russian Federation operates a three-year budget planning system, then to represent the volume of the database for three years, $200 \mathrm{mln}$ items should be multiplied by 36 months, resulting in $7 \mathrm{bln} 200 \mathrm{mln}$ items stored in the database and subject to various processing. Supervisory bodies, etc. may need the archive of information. We should add to this a separate database of general contractors and suppliers including tens of thousands of business entities, which further increases the load on Rosresurs' data processing mechanisms [10].

It is obvious, that currently not systematically observed information data stream, which is represented by billions of items and variations, greatly confuses participants of investment and construction process, and at the same time is very interesting for them, if this information would be available in a systematic way. At the same time, up-to-date equipment and technologies allowing systematization of the corresponding information, it's convenient presentation may greatly improve handling both investment plans and programs, and specific projects in the course of their implementation. But still advanced development of tools and technologies remains quite poorly evaluated as for the possibility of solving major national economic problems.

3. The difficulty of creating a new mechanism for monitoring cost of production resources is not only the need to maintain the "Big Data", but also the methods of regular collection of initial data. To solve this problem, we should use a special method of Rosresurs state institution interaction with enterprises involved in public procurement as suppliers of resources, works and services. This method is based on the principle implying that the federal cost monitoring is one of the fundamental sections of the cost engineering and in the federal program scale is a set of measures to track actual purchase and sale of material resources in construction and other spheres, to create and regularly update centralized databases (based on "Big Data" principles) with information about the current cost of different kinds of resources and to provide to the interested parties, as well as make publicly available information bulletins and reports allowing justifying planned investment costs, making cost estimates and final estimate calculations in construction. To implement the full monitoring mechanism, Rosresurs state institution should interact with the following participants of production and economic activity:

- Unified information system in the field of procurement; 
- Online trading platforms of public procurement (Sberbank-AST; Zakazrf.ru online trading system; RTS-tender online trading platform; "State Procurement" MICEX online trading system; UOTP Unified Online Trading Platform);

- Developers of accounting software in enterprises (1C, 1C-Rarus, Parus, Galaktika, etc.);

- Developers of software for making estimates;

- State customer services implementing capital-intensive construction programs;

- General contractors working on state contracts for construction works;

- Construction companies operating on the market of share construction within 214-FL;

- Companies implementing construction projects the state's share in which exceeds $50 \%$;

1)- Companies supplying construction materials, products and structures (construction resources) in the wholesale and retail markets.

\section{Discussion}

Rosresurs activities are aimed at meeting economic interests of the following parties of economic relations:

- Federal and regional ministries planning and developing investment programs of capital construction, repairs and renovation of real estate;

- Tax authorities monitoring suspicious business operations of enterprises;

- The state customer services, design, survey, and construction enterprises using information on the current cost of construction resources to plan investment costs, make estimate documentation, calculate planned and actual costs, etc.

As part of its functions, Rosresurs institution has the following basic competencies:

- Interaction and development of common rules of trading and auctions with the operators of online trading platforms of public procurement;

- Certification of commercial enterprises providing services of construction, repair and reconstruction of real estate, as well as involved in supply of construction resources for investment and construction projects they implement.

\section{Conclusion}

Isolation of a separate body for the management of the monitoring cost of building resources is a new approach in the Russian practice, and involves the development of special tools and techniques. The totality of these methods is based on serious scientific and practical base unit that requires separate investigation and will be implemented in the following works.

\section{References}

1. A.A. Gorobnyak, Economy and Entrepreneurship, 8, 618-621 (2014)

2. A.A. Gorobnyak, Online Journal Naukovedenie, 3 (2014)

3. Z.I. Ivanova, O.V. Yudenkova, A.D. Ishkov, E.A. Shnyrenkov, International Education Studies. 5, 232-239 (2015)

4. A.D. Ishkov, T.N. Magera. Procedia Engineering, 117, 148-153 (2015)

5. M.I. Kamenetskii, N.Y. Yaskova, Studies on Russian Economic Development, 26(2), 124-131 (2015)

6. V.S. Kanhva, Economy and Entrepreneurship, 5-2, 902-905 (2015) 
7. V.V. Sokolov, N.Y. Yaskova, Scientific Review, 6, 605-609 (2012)

8. Y. Panibratov, A. Larionov, Applied Mechanics and Materials, 8, 725-726 (2015)

9. Y. Panibratov, A. Larionov, World Applied Sciences Journal, 13, 144-148 (2013)

10. N.Y. Yaskova, D.N. Silka, Business activity management in a mixed construction sector, MGSU, Moscow (2013) 